\title{
Development of a sensitive novel diagnostic kit for the highly pathogenic avian influenza $A$ $(\mathrm{H} 5 \mathrm{~N} 1)$ virus
}

\author{
Yasuko Tsunetsugu-Yokota ${ }^{1,2^{*}}$, Kengo Nishimura ${ }^{3}$, Shuhei Misawa ${ }^{3}$, Mie Kobayashi-Ishihara ${ }^{1}$, Hitoshi Takahashi ${ }^{4}$, \\ Ikuyo Takayama ${ }^{4}$, Kazuo Ohnishi', Shigeyuki Itamura ${ }^{4}$, Hang LK Nguyen ${ }^{5}$, Mai TQ Le ${ }^{5}$, Giang T Dang ${ }^{6}$, \\ Long T Nguyen ${ }^{6}$, Masato Tashiro ${ }^{4}$ and Tsutomu Kageyama ${ }^{4}$
}

\begin{abstract}
Background: Sporadic emergence of the highly pathogenic avian influenza (HPAI) H5N1 virus infection in humans is a serious concern because of the potential for a pandemic. Conventional or quantitative RT-PCR is the standard laboratory test to detect viral influenza infections. However, this technology requires well-equipped laboratories and highly trained personnel. A rapid, sensitive, and specific alternative screening method is needed.

Methods: By a luminescence-linked enzyme immunoassay, we have developed a H5N1 HPAl virus detection kit using anti-H5 hemagglutinin monoclonal antibodies in combination with the detection of a universal NP antigen of the type A influenza virus. The process takes 15 minutes by use of the fully automated luminescence analyzer, POCube.

Resutls: We tested this H5/A kit using 19 clinical specimens from 13 patients stored in Vietnam who were infected with clade 1.1 or clade 2.3.4 H5N1 HPAI virus. Approximately $80 \%$ of clinical specimens were H5-positive using the POCube system, whereas only $10 \%$ of the H5-positive samples were detected as influenza A-positive by an immunochromatography-based rapid diagnostic kit.
\end{abstract}

Conclusions: This novel H5/A kit using POCube is served as a rapid and sensitive screening test for H5N1 HPAl virus infection in humans.

Keywords: H5 hemagglutinin, Highly pathogenic avian influenza virus, Rapid influenza diagnosis, Monoclonal antibody, Clinical specimens

\section{Background}

Influenza viruses belong to the Orthomyxovirus family, whose genome is composed of eight segments of negative-sense RNA encoding 12 proteins. Two major glycoproteins, hemagglutinin (HA) and neuraminidase (NA), are located on the viral envelope, and 16 HA subtypes and 9 NA subtypes of avian influenza A have been identified on the basis of their antigenicities $[1,2]$. There are three types of influenza virus, namely, A, B, and C.

\footnotetext{
* Correspondence: yyokota@nih.go.jp

'Department of Immunology, National Institute of Infectious Diseases, Shinjuku, Tokyo 162-8640, Japan

${ }^{2}$ Department of Medical Technology, School of Human Sciences, Tokyo University of Technology, 5-23-22 Nishi-Kamata, Ohta-ku, Tokyo 144-8535, Japan

Full list of author information is available at the end of the article
}

Influenza A (both H1N1 and H3N2 subtypes) and influenza B viruses circulate among the human population each year and are the causative agents of seasonal flu. There have been several pandemics of influenza A infections, which have resulted in the deaths of many humans and animals $[2,3]$. The high variability of influenza A viruses is driven by frequent mutations in genomic RNA (drift) and by genetic reassortment among avian, porcine, and human strains [4]. This has hampered the development of a universal cross-protective flu vaccine.

The 2003 and 2004 outbreaks of the highly pathogenic avian influenza (HPAI) virus of subtype H5N1 that occurred in poultry and wild birds were genetically traced back to the H5N1 HPAI virus that caused the first outbreak in Hong Kong in 1997, and also those of 2001 
and 2002 [5]. This report stated that although the H5N1 HPAI virus remained endemic to that region, it had the potential to become pandemic. The H5N1 HPAI virus has occasionally crossed the species barrier to humans in Asia, resulting in human fatalities [6,7], the first of which was recorded in Vietnam in December 2003 [8]. Numerous clinical cases of H5N1 HPAI virus infections have since been reported in Vietnam, and the disease has spread to other countries in Southeast Asia and the Middle East such as Indonesia, Cambodia, Thailand, Egypt, and Turkey [7,9].

The H5N1 HPAI virus has evolved into many phylogenetically distinct clades and subclades, and these diverse lineages have been largely geographically separated since 2005 [9]. During 2007 in northern Vietnam, the clade 1 virus was displaced by the clade 2.3 .4 strain that has a different antiviral susceptibility profile $[10,11]$. The diversity of this virus is continuing to expand $[3,12,13]$. Although the earlier endemic outbreak of the avian H5N1 HPAI virus appears to be under control, the threat of a human influenza pandemic remains.

PCR-based molecular tests are one of the most sensitive ways to detect the influenza virus, and conventional and real-time RT-PCR methods have been developed to diagnose H5N1 HPAI virus infections in humans [14-16]. However, only centralized and well-equipped laboratories with trained personnel can perform these analyses. Viral antigen detection using antibodies (Abs) offers an easier and quicker diagnostic test; however, commercially available rapid detection kits for influenza A and B have poor clinical sensitivity for the identification of H5N1 HPAI infection [9]. Using previously prepared monoclonal antibodies (mAbs) against influenza A virus HA of the H5 subtype [17], we developed a rapid, sensitive, and H5N1 HPAI virus-specific diagnostic test kit for H5 HA in combination with detection of the universal NP antigen of type A influenza (H5/A kit), which is processed by a compact and fully automated luminescence analyzer, POCube (Toyobo Co Ltd., Osaka, Japan). In this study, we evaluated this novel H5/A diagnostic kit using clinical specimens infected with the H5N1 HPAI virus (genetically confirmed) in Vietnam and demonstrated the sensitive dual detection of H5 HA and type A nucleoprotein (NP) antigens for the first time. Despite of a limited number of available $\mathrm{H} 5 \mathrm{~N} 1$ clinical specimens, our results strongly suggest that this diagnostic test is a useful tool in the rapid and reliable identification of H5N1 HPAI virus infections.

\section{Methods}

\section{POCube system}

The POCube is a fully automated and compact immunological analyzer developed by Toyobo Co. Ltd, which is intended to support the Point-of-Care Testing (POCT) system in clinics. The POCube analyzer is relatively small $(280 \times 310 \times 275 \mathrm{~mm})$, easy to operate, and rapidly measures antigen-Ab complexes by the sensitive detection of luminescence (Figure 1). The POCube system has been used in clinics to detect $\mathrm{C}$-reactive protein (CRP), prostate antigen, influenza $\mathrm{A}$ and $\mathrm{B}$ viruses, respiratory syncytial virus, in combination with kits authorized by the Ministry of Health, Labour and Welfare in Japan. The principle of the POCube system is to use two mAbs and/or polyclonal Abs that have distinct specificities, where one is biotinylated and the other is conjugated to alkaline phosphatase (ALP). The immune complexes are trapped by an anti-biotin Ab-coated filter membrane in a reaction vessel and the activity of ALP is measured by luminescence output. The whole process takes 5-15 min (depending on the kit), the result is expressed as a luminescence count, and a clinical diagnosis is indicated as "positive" or "negative".

The H5/A kit consists of one cartridge containing two reaction vessels with an anti-biotin Ab-coated filter membrane and following solutions in each compartment of the reservoir tank sealed with an aluminum sheet (Figure 1); a biotinylated anti-H5 HA mAb and a ALPconjugated anti-H5 HA mAb solutions to detect H5 HA antigens, a commercially available biotinylated and ALPconjugated $\mathrm{mAb}$ set against the type A influenza NP antigen, washing buffer, and a luminescent substrate (APS-5, Lumigen, Inc., Southfield, MI). Up to $180 \mu \mathrm{l}$ of sample is placed into the first empty reservoir tank within the cartridge. When the POCube operation is started, the sample solution is transferred to reservoir tanks containing each set of Abs and allowed to react at $40^{\circ} \mathrm{C}$ before the immune complex consisting of antigen, biotinylated $\mathrm{Ab}$ and ALP-conjugated $\mathrm{Ab}$ is formed. Each reaction solution is then transferred to each vessel and trapped on an anti-biotin Ab-coated filter membrane. The filter membrane is washed with buffer in the tank, substrate is added to each vessel, and the chemiluminescence is measured. The program is set to indicate a positive or negative result for $\mathrm{H} 5 \mathrm{HA}$ and type A influenza virus antigens based on a predetermined cut-off index set that is calculated by adding four standard deviations (SDs) to the average of eight measurements for the negative control. The luminescence counts for eight negative controls in the lot used to test clinical specimens from Vietnam were 1939-2717 (average, 2242; SD, 292) for H5 HA and 1779-2354 (average, 2027; SD, 221) for type A influenza. Thus, the cut-off indices were set at 3410 and 2911, respectively.

The sensitivity of the kit was compared with that of the ESPLINE ${ }^{\oplus}$ Influenza A\&B-N (Fujirebio, Inc., Tokyo, Japan) kit, which is a commercially available rapid influenza diagnostic test (RIDT). This immunochromatography (IC)-based kit is meant to diagnose infection by all type A influenza viruses, including H5N1. However, 


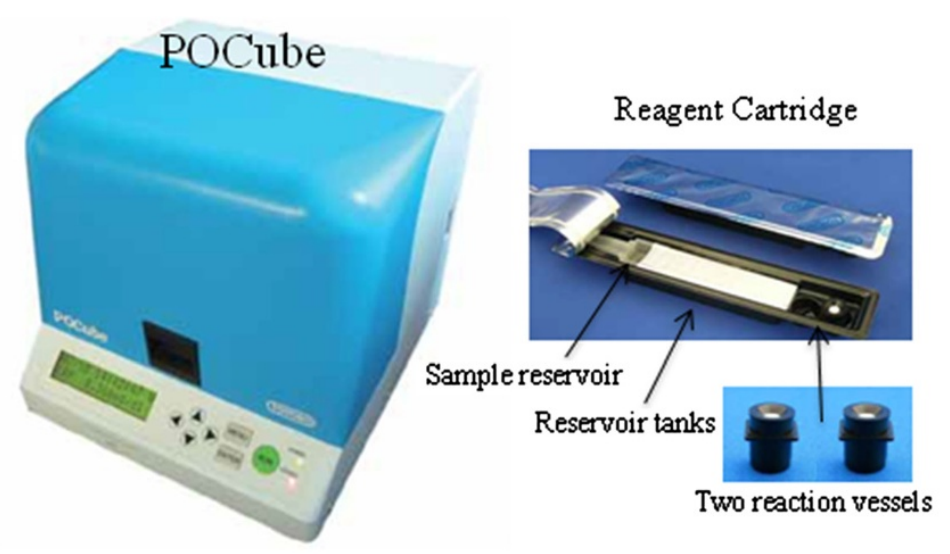

\section{ChemiLuminescent Enzyme Immuno Assay (CLELA)}

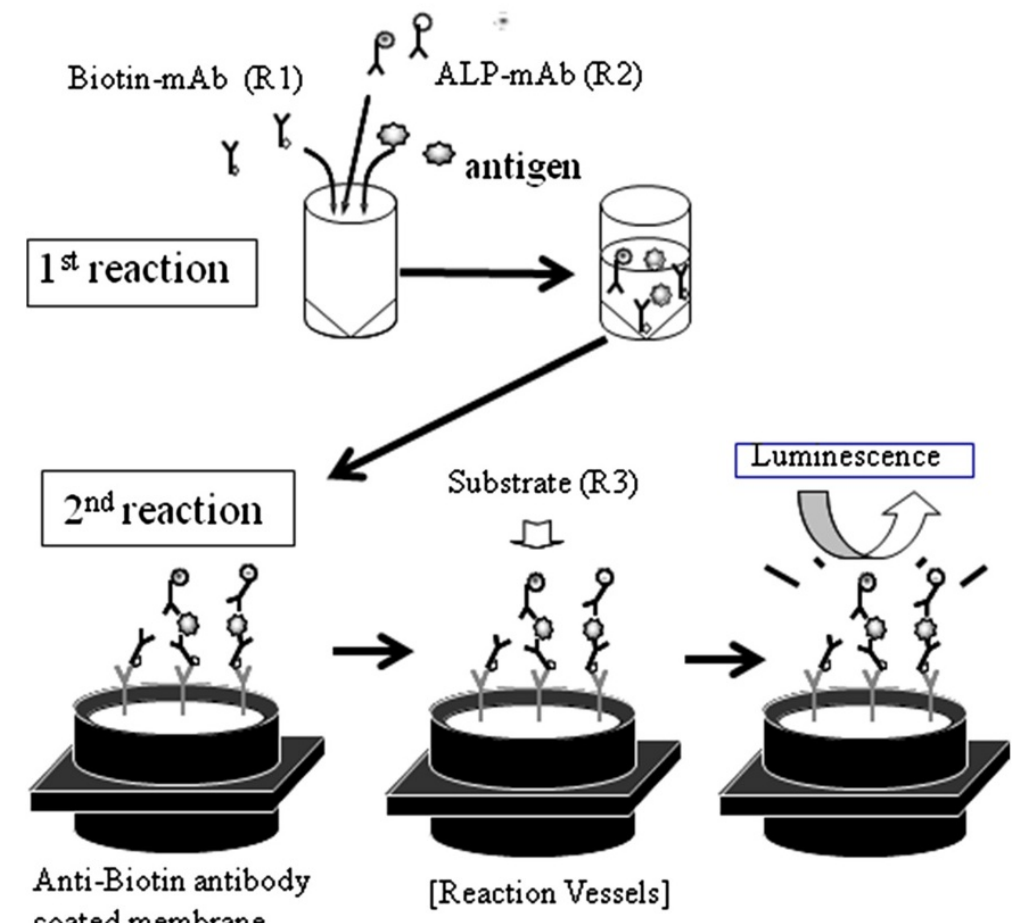

Figure 1 Principle of the POCube system. POCube is a fully automated chemiluminescence analyzer. In the H5/A kit, two Abs were incorporated, namely, one for $\mathrm{H} 5 \mathrm{HA}$ and the other for type A NP antigens of the influenza virus. One of the Abs is biotinylated and the other is conjugated to ALP. A sample is loaded into a reservoir tank in the cartridge, which is placed in the machine along with two reaction vessels. When the complex of antigen and two Abs is formed, it is trapped on an anti-biotin Ab-coated membrane in the reaction vessels. The membrane is then washed, a luminescent substrate for ALP is added, and the emitted luminescence is measured. Using the appropriate program, POCube automatically performs each of these steps, and the result is displayed as either positive or negative. Alternatively, the luminescence counts can be provided, if preferred.

because this kit uses an NP-specific antibody, it cannot discriminate $\mathrm{H} 5 \mathrm{~N} 1$ from other subtypes.

\section{Virus preparation}

The A/Vietnam/1194/2004 (NIBRG-14) virus, which has a modified $\mathrm{HA}$ gene and an NA gene derived from the HPAI A/Vietnam/1194/2004 (H5N1) virus within the backbone of six other internal genes of A/Puerto Rico/8/
34 (PR8), as well as other modified $\mathrm{H} 5 \mathrm{~N} 1$ viruses, $\mathrm{A} /$ Indonesia/5/2005 (Indo5/PR-8-RG2), A/turkey/Turkey/ 1/2005 (NIBRG-23), and A/Anhui/01/2005 (Anhui01/ PR8-RG5), were provided by the National Institute for Biological Standards and Controls (Potters Bar, UK). The following subtypes of influenza A viruses were also used to evaluate the specificity of the POCube H5/A kit and were obtained from the Influenza Virus Research Center 
of the National Institute of Infectious Diseases (NIID), Tokyo, Japan: A/duck/Alberta/35/76 (H1N1), A/duck/ Germany/1215/73 (H2N3), A/duck/Ukraine/1/63 (H3N8), A/duck/Czechoslovakia/56 (H4N6), A/turkey/Massachusetts/ 3740/65 (H6N2), A/duck/Hong Kong/301/78 (H7N1), A/ turkey/Ontario/6118/68 (H8N4), A/turkey/Wisconsin/1/ 66 (H9N2), A/chicken/Germany/N/49 (H10N7), A/duck/ England/56 (H11N6), A/duck/Alberta/60/76 (H12N5), A/ gull/Maryland/704/77 (H13N6), A/mallard/Gurjev/263/82 (H14N5), and A/duck/Australia/341/83 (H15N8). All viruses were propagated in the allantoic cavity of 10-dayold embryonated chicken eggs. The virus titer and RNA copy number of the matrix gene were determined by the $50 \%$ tissue culture infective dose $\left(\mathrm{TCID}_{50}\right)$ using MadinDarby Canine Kidney (MDCK) cells and by quantitative real-time RT-PCR as described previously [18], respectively.

\section{Clinical samples}

Throat swabs or tracheal aspirates were collected at the point of admission from patients with clinical H5N1 virus infections in Northern Vietnam from 2007 to 2010. Clinical specimens were diluted in about $2 \mathrm{ml}$ of viral transport medium (VTM) consisting of MEM medium supplemented with $1 \%$ of $2.92 \%$ L-glutamine, $1 \%$ of Penicillin- Streptomycin $(10,000 \mathrm{U} / \mathrm{ml}$ and $10,000 \mu \mathrm{g} / \mathrm{ml}$, respectively), $1.5 \%$ of $37.5 \% \mathrm{NaHCO}_{3}$ and $0.05 \%$ of $250 \mu \mathrm{g} / \mathrm{ml}$ Fungizon (all from Life Technologies, Carlsbad, CA), packed into a cooling box and sent to the National Influenza Center, National Institute of Hygiene and Epidemiology (NIHE) for H5N1 HPAI virus detection by conventional RT-PCR. Clinical specimens (nasal and throat swabs) from Southern Vietnam collected in 2009 and 2012 were diluted in about $2 \mathrm{ml}$ of VTM and sent to the National Influenza Center, Pasteur Institute in Ho Chi Minh City (PI-HCMC) for H5N1 HPAI virus detection by real-time RT-PCR. After a part of clinical specimen was used for RNA extraction, the remaining volume was aliquoted into cryotubes and maintained at $-80^{\circ} \mathrm{C}$ until further analysis. The collection of clinical samples was approved by the institutional review boards of NIHE and PI-HCMC. All nasopharyngeal aspirates from patients, including seasonal and non-influenza, were collected after obtaining patient's written informed consent.

\section{Results and discussion}

Different combinations of anti-H5 HA mAbs [17] and a pair of biotinylated OM-b and ALP-conjugated 1C10 mAbs were selected for $\mathrm{H} 5 \mathrm{HA}$ detection.

The H5/A kit contains two sets of mAb mixtures to detect H5 HA simultaneously with NP antigens which are common to all influenza A viruses. This combination is important for the definitive diagnosis of H5 HPAI virus infection. When a clinical specimen is loaded into a reservoir tank in the cartridge, which is placed in the machine along with two reaction vessels, an automatic diagnosis for H5N1 HPAI virus infection is provided (Figure 1). To determine the sensitivity of the H5/A kit, inactivated H5N1 HPAI virus of representative clades (Table 1) were used. The quantities of viruses were determined by $\mathrm{TCID}_{50}$ and quantitative real-time RTPCR targeting the universally conserved matrix gene of influenza A. These viruses were serially 10 -fold diluted and the luminescence counts were measured. Then, the virus $\mathrm{TCID}_{50}$ titers at each dilution were calculated and plotted as shown in Figure 2. The dotted line indicates the lowest detection threshold, which was determined by adding four standard deviations to the average of eight measurements of the negative control. Thus, the POCube detected these viruses at a titer equivalent to $10^{1}-10^{3} \mathrm{TCID}_{50}$.

We also confirmed that the kit detected type A antigens, but not $\mathrm{H} 5$ antigens, in all other subsets of type $\mathrm{A}$ influenza viruses examined (H1N1, H2N3, H3N8, H4N6, H6N2, H7N1 H8N4, H9N2, H10N7, H11N6, H12N5, H13N6, H14N5, and H15N8) including strains recently endemic in Japan (mostly H1N1pdm or type B), indicating that the kit is highly specific to H5 HA (data not shown). Furthermore, we tested clinical swab specimens taken from 15 seasonal influenza and 30 non-influenza patients and found no false positives of H5. Thus, the POCube system offers a simple, safe, and rapid diagnostic system, and is expected to be highly sensitive compared with existing commercial kits that use immunochromatography (IC) technology.

We tested clinical specimens (throat swabs) from nine patients infected with the H5N1 HPAI virus (identification confirmed by molecular diagnosis using RT-PCR) in NIHE during 2007 to 2010 (clade 2.3.4) and compared the detection rate of our H5/A kit by POCube with that of the commercially available rapid influenza diagnostic test (RIDT), (Table 2). The clade was confirmed by genetic analysis of MDCK cells and/or embryonated egg isolation (data not shown). Luminescence counts of POCube were categorized as positive or negative as described in the Methods. In 2007, clinical specimens were collected at two time points from patient A, whereas they were only collected once from each of the other patients (B-I). All the specimens were already

Table 1 H5N1 viruses used for titration

\begin{tabular}{ccccc}
\hline & Virus strain & Clade & $\begin{array}{c}\mathbf{T C I D}_{\mathbf{5 0}} / \\
\mathbf{5 0} \boldsymbol{\mu l} \\
\left(\mathbf{L o g}_{\mathbf{1 0}}\right)\end{array}$ & $\begin{array}{c}\text { RNA } \\
\mathbf{c o p i e s} \\
(\times \mathbf{1 0} \mathbf{1 0} / \mathbf{m l})\end{array}$ \\
\hline 1 & A/Nietnam/1194/2004 (NIBRG-14) & 1.1 & 7.0 & 2.88 \\
2 & A/Indonesia/5/2005 (PR8-IBCDC) & 2.1 .3 .2 & 7.4 & 3.81 \\
3 & A/turkey/Turkey/1/2005 (NIBRG-23) & 2.2 .1 & 5.9 & 1.60 \\
4 & A/Anhui/1/2005 (PR8-IBCDC RG-5) & 2.3 .4 & 8.3 & 3.73 \\
\hline
\end{tabular}




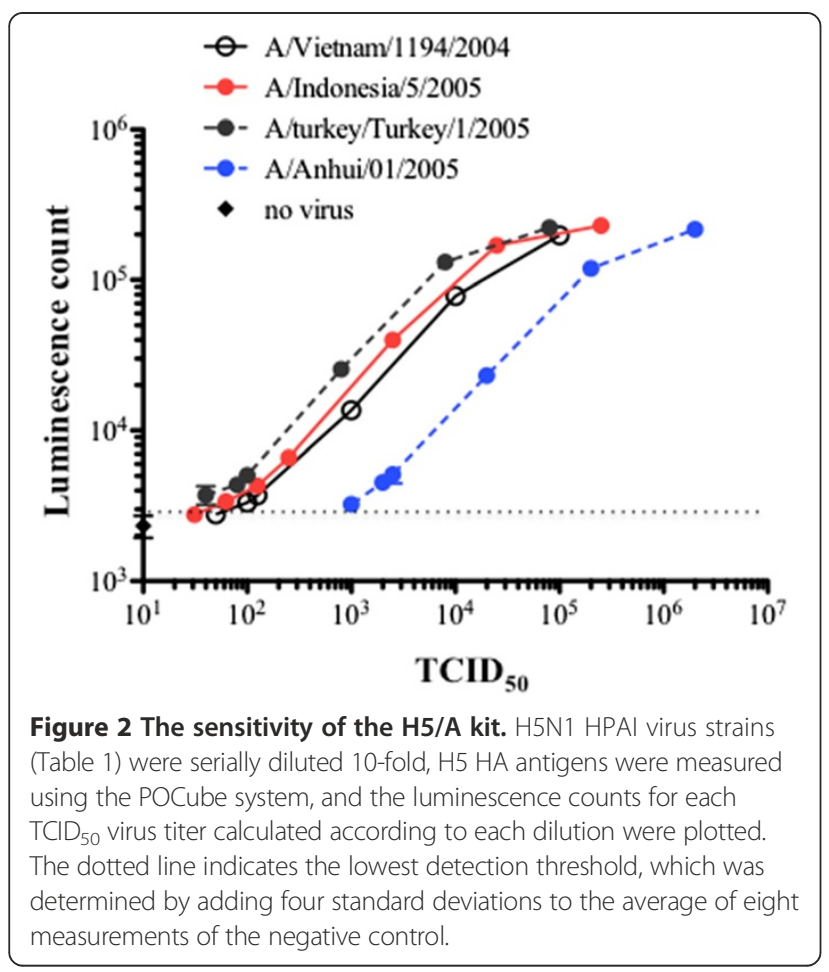

diluted approximately 40-fold with VTM. We re-examined these clinical specimens for H5 HA RNA using conventional RT-PCR to assess the quality of the frozen samples: all were positive. One of these 10 samples (sample No. 9 of patient $\mathrm{H}$ ) was H5-negative but type A-positive (Table 2), indicating that the abundance of viral particles was very

Table 2 Detection of H5N1 HPIA virus in clinical specimens in NIHE, Hanoi (clade 2.3.4)

\begin{tabular}{lccccc}
\hline Year & Patient ID & Test no. & \multicolumn{2}{c}{ POCube H5/A } & RIDT $^{2}$ \\
\cline { 3 - 5 } & & & H5 HA & A NP & \\
\hline \multirow{2}{*}{2007} & A & 1 & + & + & + \\
& & 2 & + & - & - \\
& B & 3 & + & + & - \\
& C & 4 & + & + & - \\
& D & 5 & + & + & $+/{ }^{3}$ \\
& E & 6 & + & + & - \\
& F & 7 & + & + & - \\
& G & 8 & + & + & - \\
& H & 9 & - & + & - \\
& I & 10 & + & + & - \\
& \% positive & & 90 & 90 & 10
\end{tabular}

"The POCube machine shows the results for $\mathrm{H} 5$ and type A viruses as "+" or "-" based on a predetermined cut-off index set (calculated as described in the "Methods").

${ }^{2}$ RIDT: commercial kit detecting universal NP antigen of influenza A virus (ESPLINE ${ }^{\oplus}$ Influenza A\&B-N)

${ }^{3}$ Uncertain.
Table 3 Detection of H5N1 HPIA virus in clinical specimens in PI-HCMC (clade 1.1)

\begin{tabular}{|c|c|c|c|c|c|c|}
\hline \multirow[t]{2}{*}{ Year } & \multirow[t]{2}{*}{ Patient ID } & \multirow[t]{2}{*}{ Test no. } & \multirow[t]{2}{*}{ Specimen } & \multicolumn{2}{|c|}{ POCube H5/A } & \multirow[t]{2}{*}{ RIDT } \\
\hline & & & & $\mathrm{H} 5 \mathrm{HA}$ & A NP & \\
\hline \multirow{4}{*}{2009} & J & 11 & Throat & + & + & - \\
\hline & & 12 & Throat & + & + & \\
\hline & & 13 & Nasal & + & + & - \\
\hline & & 14 & Serum & + & + & - \\
\hline \multirow{6}{*}{2012} & k & 15 & Throat & + & + & + \\
\hline & L & 16 & Throat & - & - & - \\
\hline & & 17 & Nasal & + & + & \\
\hline & M & 18 & Throat & + & - & - \\
\hline & & 19 & Nasal & + & + & - \\
\hline & & \multicolumn{2}{|c|}{$\%$ positive } & 88.9 & 77.8 & 11.1 \\
\hline
\end{tabular}

low. One sample (No. 2 of patient A) was H5-positive but type A-negative. The quantity of viral particles was lower in this sample (No. 2) than in the sample (No. 1) that was collected at an earlier time point from the same patient (luminescence count of type A was 3,582 in sample No. 2 vs. 122,693 in sample No. 1). By contrast, a widely used commercially available RIDT based on IC using an antiNP Ab showed very poor sensitivity, with only $10 \%$ of samples indicating a positive result. Furthermore, because the influenza NP is highly conserved, this kit cannot discriminate the $\mathrm{A} / \mathrm{H} 5 \mathrm{~N} 1$ subtype from other influenza virus subtypes.

The H5/A kit was also evaluated using nine clinical specimens collected from one patient (J) in 2009 and from three patients (K-M) in 2012 (Table 3). These specimens were stored at the PI-HCMC after H5N1 HPAI virus (clade 1.1) infection was confirmed by genetic analysis of MDCK cells (data not shown). In patient J, throat swabs taken at two time points, a nasal swab, and a serum sample were all H5-positive and had similar luminescence counts of 5,282, 5,358, 5,344, and 6,448, respectively. In patient $\mathrm{L}$, a throat swab was $\mathrm{H} 5$ - and type A-negative, whereas a nasal swab was positive for both. In patient $\mathrm{M}$, a throat swab was $\mathrm{H} 5$-positive and type A-negative, whereas a nasal swab was $\mathrm{H} 5$ - and type A-positive. These results suggest that secretion of the

Table 4 Summary of H5N1 HPIA virus detection in clinical specimens from Vietnam

\begin{tabular}{|c|c|c|c|c|c|c|}
\hline \multirow{3}{*}{ H5N1 } & \multicolumn{4}{|c|}{ POCube H5/A } & \multirow{3}{*}{$\begin{array}{c}\% \text { positive } \\
\text { by POCube } \\
\text { H5/A kit }\end{array}$} & \multirow{3}{*}{$\begin{array}{c}\% \text { positive } \\
\text { by RIDT }\end{array}$} \\
\hline & \multirow{2}{*}{$\begin{array}{c}\text { Positive } \\
+/+\end{array}$} & \multirow{2}{*}{$\begin{array}{c}\text { Negative } \\
\text {-/- }\end{array}$} & \multicolumn{2}{|c|}{ Suspicious } & & \\
\hline & & & $+/-$ & $-/+$ & & \\
\hline Clade 2.3.4 & 8 & 0 & 1 & 1 & 80.0 & 10 \\
\hline Clade 1.1 & 7 & 1 & 1 & 0 & 77.8 & 11.1 \\
\hline Total & 15 & 1 & 2 & 1 & 78.9 & 10.5 \\
\hline
\end{tabular}


virus is more abundant in the nasal mucosa than in the throat, and are not consistent with previous reports $[19,20]$. Also, the timing for sampling may affect the detection efficiency. However, because the number of samples tested in this study was very small, further testing is needed. The findings indicate that when $\mathrm{H} 5 \mathrm{~N} 1$ HPAI virus infection is suspected, it is important to collect samples from more than one anatomical location (i.e., throat and nose) and/or at more than one time point.

When samples are H5-positive but type A-negative, such as was the case for patient $M$ (luminescence counts of $\mathrm{H} 5$ and type A were 4,071 and 2,622, respectively), the test needs to be repeated or confirmed by genetic analysis. This may occur when the level of virus antigen is at the threshold of detection, such as was the case for sample No. 2 of patient A. Again, the commercially available RIDT showed poor sensitivity, with only one of nine samples testing positive for type A.

Table 4 shows a summary of the results of the POCube H5/A kit test in samples collected from Vietnam, which detected $77.8 \%$ and $80.0 \%$ of clade 1.1 and clade 2.3 .4 H5N1 HPAI virus infections, respectively. In these samples, the POCube test detected $78.9 \%$ of H5N1 HPAI virus infections, whereas the RIDT detected only $10.5 \%$. This was probably because POCube is a highly sensitive chemiluminescence detection system that uses mAbs with a high affinity to H5 HA and also analyzes a much larger sample volume than the RIDT (up to $180 \mu \mathrm{l}$ for POCube vs. about $5 \mu \mathrm{l}$ for RIDT). Considering that only one in 19 samples tested negative for both $\mathrm{H} 5$ and $\mathrm{A}$ antigens, the POCube H5/A kit is highly useful to detect H5N1 HPAI virus infections in clinical settings. In this study, samples were diluted in VTM (about $2 \mathrm{ml}$ ); however, we believe the detection rate will improved even further if clinical swabs are tested with a reduced volume of this medium.

H5 HA HPAI virus detection using POCube and the H5/A kit is a highly sensitive and simple rapid diagnostic system that can be completed within 15 minutes. During the preparation of this manuscript, Sakurai et al. reported a 10-100-fold more sensitive detection of H5 HA using fluorescent beads and an improved IC method [21]; however, the clinical effectiveness of this method remains to be evaluated. We recently determined the epitopes of our anti-H5HA mAbs and found that OM-b, one of mAbs used for the H5/A kit, was broadly reactive to various clades of H5N1 influenza virus isolates in Asia, indicating that ther kit is quite useful for the diagnosis of H5N1 infection in Asian counties [22].

\section{Conclusions}

The POCube system using the H5/A kit is useful for the rapid detection of H5N1 HPAI virus infections in humans in hospitals and other clinical settings where technical resources are limited.

\section{Abbreviations}

HA: Hemmagglutinin; NA: Neuraminidase; NP: Nucleoprotein; HPAl: Highly pathogenic avian influenza; ALP: Alkaline phosphatase; RIDT: Rapid influenza diagnostic test; $\mathrm{TCID}_{50}$ : 50\% tissue culture infectious dose; VTM: Viral transport medium.

\section{Competing interests}

KN and SM are research staffs in Toyobo Co.Ltd. and collaborated with YYY, KO and TK in NIID (a government research institute) for this study, which was formally supported by a grant from the Health Science Foundation of the Ministry of Health, Labor and Welfare of Japan (KHC1218). The patent of H5/A kit was filed by Toyobo Co. Ltd and NIID. This may not cause any competing non-financial interests were they to become public after the publication of this manuscript.

All other authors declare no potential conflicts of interest.

\section{Authors' contributions}

YTY, KN, SM and KT determined the protocol for the assay. HLKN, MTQL GTD, LTN prepared clinical specimens and helped YTY and KT for the analysis. MKI, HT and HT participated in the design of the study and helped to draft the manuscript. KO, SI and MT helped to analyze the results and finalize the manuscript. All authors read and approved the final manuscript.

\section{Authors' information}

YTY worked in NIID for this study and recently moved to the Department of Medical Technology, School of Human Sciences, Tokyo University of Technology, 5-23-22 Nishi-Kamata, Ohta-ku, Tokyo 144-8535, Japan.

\section{Acknowledgments}

We thank all our colleagues in the First laboratory, and others in the Department of Immunology, NIID Japan, for their help and discussions. This work was supported by a grant from the Health Science Foundation (KHC1218) of the Ministry of Health, Labor and Welfare of Japan.

\section{Author details}

1 Department of Immunology, National Institute of Infectious Diseases, Shinjuku, Tokyo 162-8640, Japan. ${ }^{2}$ Department of Medical Technology, School of Human Sciences, Tokyo University of Technology, 5-23-22 Nishi-Kamata, Ohta-ku, Tokyo 144-8535, Japan. ${ }^{3}$ Tsuruga Institute of Biotechnology, Toyobo, Co., Ltd., Fukui 914-8550, Japan. ${ }^{4}$ National Institute of Infectious Diseases, Influenza Virus Research Center, Musashimurayama, Tokyo 208-0011, Japan. ${ }^{5}$ Department of Virology, National Institute of Hygiene and Epidemiology, Hanoi, Vietnam. ${ }^{6}$ Pasteur Institute, National Influenza Center, Ho Chi Minh City, Vietnam.

Received: 8 April 2014 Accepted: 30 June 2014

Published: 3 July 2014

\section{References}

1. Kim JK, Negovetich NJ, Forrest HL, Webster RG: Ducks: the "Trojan horses" of H5N1 influenza. Influenza Other Respir Viruses 2009, 3(4):121-128.

2. Wright P, Neumann G, Kawaoka Y: Fields Virology, vol. II, 5 edn. Philadelphia, PA: Lippincott Williams \& Wilkins, a Wolters Kluwer Business; 2007.

3. Salomon R, Webster RG: The influenza virus enigma. Cell 2009, 136(3):402-410.

4. Wille M, Tolf C, Avril A, Latorre-Margalef N, Wallerstrom S, Olsen B, Waldenstrom J: Frequency and patterns of reassortment in natural influenza A virus infection in a reservoir host. Virology 2013, 443(1):150-160.

5. Li KS, Guan Y, Wang J, Smith GJ, Xu KM, Duan L, Rahardjo AP, Puthavathana P, Buranathai C, Nguyen TD, Estoepangestie AT, Chaisingh A, Auewarakul P, Long HT, Hanh NT, Webby RJ, Poon LL, Chen H, Shortridge KF, Yuen KY, Webster RG, Peiris JS: Genesis of a highly pathogenic and potentially pandemic H5N1 influenza virus in eastern Asia. Nature 2004, 430(6996):209-213.

6. Beigel JH, Farrar J, Han AM, Hayden FG, Hyer R, de Jong MD, Lochindarat S, Nguyen TK, Nguyen TH, Tran TH, Nicoll A, Touch S, Yuen KY: Avian influenza A (H5N1) infection in humans. N Engl J Med 2005, 353(13):1374-1385.

7. Kaplan BS, Webby RJ: The avian and mammalian host range of highly pathogenic avian H5N1 influenza. Virus Res 2013, 178(1):3-11.

8. Tran TH, Nguyen TL, Nguyen TD, Luong TS, Pham PM, Nguyen $\vee$ V, Pham TS, Vo CD, Le TQ, Ngo TT, Dao BK, Le PP, Nguyen TT, Hoang TL, Cao VT, Le 
TG, Nguyen DT, Le HN, Nguyen KT, Le HS, Le VT, Christiane D, Tran TT, Menno de J, Schultsz C, Cheng P, Lim W, Horby P, Farrar J: Avian influenza A (H5N1) in 10 patients in Vietnam. N Engl J Med 2004, 350(12):1179-1188.

9. Abdel-Ghafar AN, Chotpitayasunondh T, Gao Z, Hayden FG, Nguyen DH, de Jong MD, Naghdaliyev A, Peiris JS, Shindo N, Soeroso S, Uyeki TM: Update on avian influenza $A(H 5 N 1)$ virus infection in humans. N Engl J Med 2008, 358(3):261-273.

10. Creanga A, Thi Nguyen D, Gerloff N, Thi Do H, Balish A, Dang Nguyen H, Jang Y, Thi Dam V, Thor S, Jones J, Simpson N, Shu B, Emery S, Berman L, Nguyen HT, Bryant JE, Lindstrom S, Klimov A, Donis RO, Davis CT, Nguyen T: Emergence of multiple clade 2.3.2.1 influenza A (H5N1) virus subgroups in Vietnam and detection of novel reassortants. Virology 2013, 444(1-2):12-20.

11. Le MT, Wertheim HF, Nguyen HD, Taylor W, Hoang PV, Vuong CD, Nguyen HL, Nguyen HH, Nguyen TQ, Nguyen TV, Van TD, Ngoc BT, Bui TN, Nguyen BG, Nguyen LT, Luong ST, Phan PH, Pham HV, Nguyen T, Fox A, Nguyen CV, Do HQ, Crusat M, Farrar J, Nguyen HT, de Jong MD, Horby P: Influenza A H5N1 clade 2.3.4 virus with a different antiviral susceptibility profile replaced clade 1 virus in humans in northern Vietnam. PLoS One 2008, 3(10):e3339.

12. Updated unified nomenclature system for the highly pathogenic H5N1 avian influenza viruses. [http://www.who.int/influenza/giss_laboratory/ h5n1_nomenclature/en/\%3E]

13. Webster RG, Govorkova EA: H5N1 influenza-continuing evolution and spread. N Engl J Med 2006, 355(21):2174-2177.

14. Ellis JS, Smith JW, Braham S, Lock M, Barlow K, Zambon MC: Design and validation of an $\mathrm{H} 5$ TaqMan real-time one-step reverse transcription-PCR and confirmatory assays for diagnosis and verification of influenza $\mathrm{A}$ virus H5 infections in humans. J Clin Microbiol 2007, 45(5):1535-1543.

15. Suwannakarn K, Payungporn S, Chieochansin T, Samransamruajkit R, Amonsin A, Songserm T, Chaisingh A, Chamnanpood P, Chutinimitkul S, Theamboonlers A, Poovorawan Y: Typing (A/B) and subtyping ( $\mathrm{H} 1 / \mathrm{H} 3 / \mathrm{H} 5)$ of influenza A viruses by multiplex real-time RT-PCR assays. J Virol Methods 2008, 152(1-2):25-31.

16. Yuen KY, Chan PK, Peiris M, Tsang DN, Que TL, Shortridge KF, Cheung PT, To WK, Ho ET, Sung R, Cheng AF: Clinical features and rapid viral diagnosis of human disease associated with avian influenza A H5N1 virus. Lancet 1998, 351(9101):467-471

17. Ohnishi K, Takahashi Y, Kono N, Nakajima N, Mizukoshi F, Misawa S, Yamamoto T, Mitsuki YY, Fu S, Hirayama N, Ohshima M, Ato M, Kageyama T, Odagiri T, Tashiro M, Kobayashi K, Itamura S, Tsunetsugu-Yokota Y: Newly established monoclonal antibodies for immunological detection of H5N1 influenza virus. Jpn J Infect Dis 2012, 65(1):19-27.

18. Nakauchi M, Yasui Y, Miyoshi T, Minagawa H, Tanaka T, Tashiro M, Kageyama T: One-step real-time reverse transcription-PCR assays for detecting and subtyping pandemic influenza A/H1N1 2009, seasonal influenza A/H1N1, and seasonal influenza A/H3N2 viruses. J Virol Methods 2011, 171(1):156-162.

19. de Jong MD, Simmons CP, Thanh TT, Hien VM, Smith GJ, Chau TN, Hoang DM, Chau NV, Khanh TH, Dong VC, Qui PT, Cam BV, Ha do Q, Guan Y, Peiris JS, Chinh NT, Hien TT, Farrar J: Fatal outcome of human influenza A (H5N1) is associated with high viral load and hypercytokinemia. Nat Med 2006, 12(10):1203-1207.

20. Uyeki TM: Human infection with highly pathogenic avian influenza A (H5N1) virus: review of clinical issues. Clin Infect Dis 2009, 49(2):279-290.

21. Sakurai A, Takayama K, Nomura N, Munakata T, Yamamoto N, Tamura T, Yamada J, Hashimoto M, Kuwahara K, Sakoda Y, Suda Y, Kobayashi Y, Sakaguchi N, Kida H, Kohara M, Shibasaki F: Broad-spectrum detection of h5 subtype influenza a viruses with a new fluorescent immunochromatography system. PLoS One 2013, 8(11):e76753.

22. Kobayashi-lshihara M, Takahashi $\mathrm{H}$, Ohnishi K, Nishimura K, Terahara K, Ato M, Itamura S, Kageyama T, Tsunetsugu-Yokota Y: Broad Cross-Reactive Epitopes of the H5N1 Influenza Virus Ide ntified by Murine Antibodies Against the A/Vietnam/1194/2004 Hemagglutinin. PLoS One 2014, 9(6):e99201.

doi:10.1186/1471-2334-14-362

Cite this article as: Tsunetsugu-Yokota et al:: Development of a sensitive novel diagnostic kit for the highly pathogenic avian influenza A (H5N1) virus. BMC Infectious Diseases 2014 14:362.

\section{Submit your next manuscript to BioMed Central and take full advantage of:}

- Convenient online submission

- Thorough peer review

- No space constraints or color figure charges

- Immediate publication on acceptance

- Inclusion in PubMed, CAS, Scopus and Google Scholar

- Research which is freely available for redistribution

Submit your manuscript at www.biomedcentral.com/submit
() Biomed Central 